\title{
Mortalitas dan bobot badan tiga strain ayam broiler pada kepadatan kandang yang berbeda
}

\section{Mortality and body weight for three strains of broiler chickens on different housing densities}

\author{
Asep Setiaji ${ }^{1 *}$, Nurfaizin ${ }^{2}$, Binti Ma'rifah ${ }^{1}$, Lilik Krismiyanto ${ }^{1}$ \\ ${ }^{1}$ Departemen Peternakan, Fakultas Peternakan dan Pertanian, Universitas Diponegoro, Kampus Tembalang, Semarang, 50275 \\ Jawa Tengah, Indonesia \\ ${ }^{2}$ Balai Pengkajian Teknologi Pertanian Jawa Tengah, Jl. Soekarno - Hatta KM. 26 No. 10, Bergas, Kabupaten Semarang 50552 \\ Jawa Tengah, Indonesia \\ *Email Koresponden: asepsetiaji@lecturer.undip.ac.id
}

\begin{tabular}{|c|c|}
\hline ARTICLE INFO & A B S T R A K \\
\hline Received: & \multirow{12}{*}{ 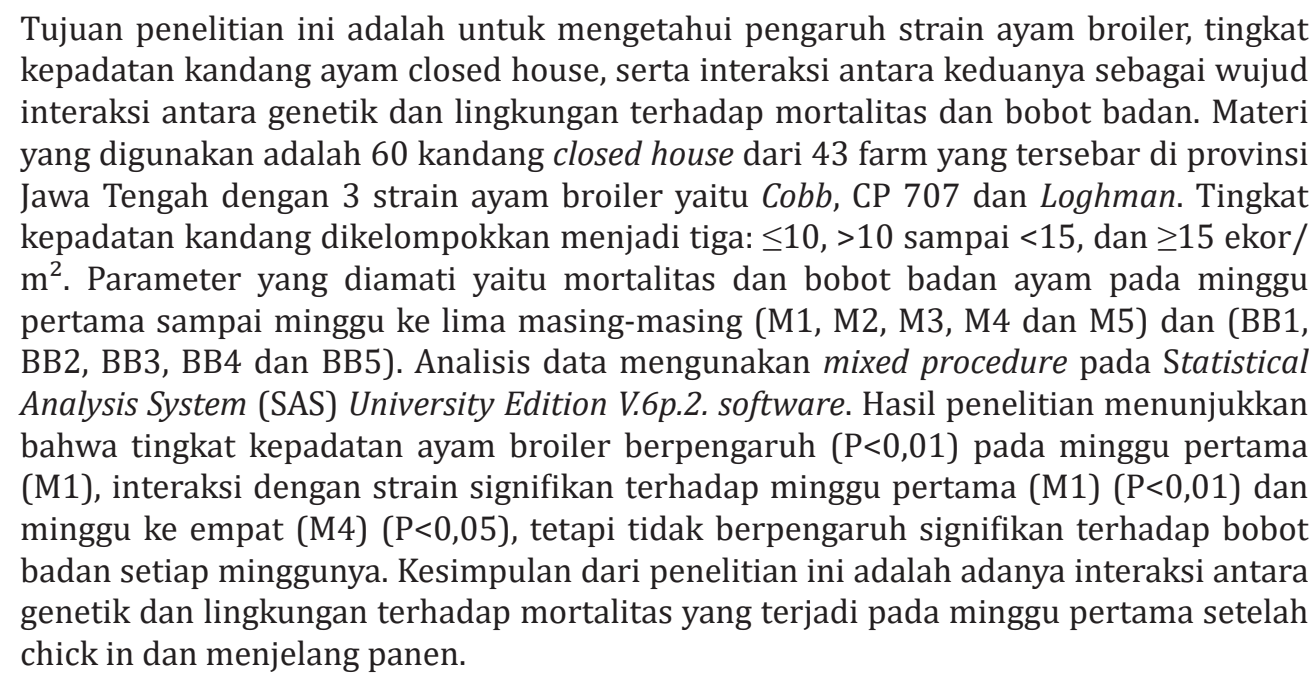 } \\
\hline 9 August 2021 & \\
\hline Accepted: & \\
\hline 14 October 2021 & \\
\hline Published: & \\
\hline 31 October 2021 & \\
\hline Kata kunci: & \\
\hline Ayam broiler & \\
\hline Bobot badan & \\
\hline Closed house & \\
\hline Kepadatan & \\
\hline Mortalitas & \\
\hline
\end{tabular}

\section{A B S T R A C T}

The aim of this study was to analyze the effects of strain, density and their interaction on mortality and body weight of broiler chicken raised in the closed houses. The data was obtained from 60 broiler farms in the Central Java province. Three strains were Cobb, CP 707, and Loghman. The density level was classified into three groups: $\leq 10,>10$ to $<15$, and $\geq 15$ birds $/ \mathrm{m} 2$. Parameters observed were mortality and body weight in the first week to the fifth week (M1, M2, M3, M4, and M5) and (BB1, BB2, BB3, BB4 dan

Key words: Broiler Chicken

Body Weight

Closed house

Density

Mortality $B B 5)$, respectively. Test of significance effect for strain and density was performed using Mixed procedure of Statistical Analysis System (SAS) University Edition V.6p.2. software. The results showed that density was significant $(P<0,01)$ on first week $(M 1)$, their interaction was $(P<0,01)$ on $M 1$ and $(P<0,05)$ on fourth week $(M 4)$, but not significant on body weight. Conclusion from this study there was intercation between genetic and environment on mortality one week after chick in and nearly harvesting.

\section{PENDAHULUAN}

Ayam broiler pertama kali diperkenalkan masuk ke Indonesia pada tahun 1950. Popularitasnya terus meningkat dan menjadi primadona pada tahun 1980. Dekade terakhir ini pemeliharaan ayam broiler semakin maju dengan adanya teknologi kandang sistem closed house (Susanti, Dahlan, \& Wahyuning, 2016). Peternak sudah beralih dalam pemeliharaan yang sebelumnya secara open house ke sistem closed house. Pemeliharaan ayam broiler 
menggunakan hasil persilangan berbagai strain unggul. Beberapa strain yang masuk dan diternakkan di Indonesia antara lain: Hubbard, Cobb, Ross, Loghman, dan Hybro, dengan kelemahan dan keunggulan masing-masing (Muwarni, 2010).

Kepadatan kandang adalah indikator dalam menentukan jumlah ayam yang akan dipelihara dalam kandang dengan luas tertentu. Kepadatan kandang sangat berpengaruh terhadap performan dan mortalitas ayam broiler. Kepadatan yang terlalu tinggi memiliki efek negatif terhadap peningkatan suhu dan kelembapan dalam kandang serta sirkulasi udara yang buruk (Mahmud, Afnan, Ekastuti, \& Arief, 2017). Kepadatan kandang yang tinggi juga akan menurunkan aktivitas ayam sehingga berpengaruh pada kesehatan kaki (Hall, 2001). Kepadatan ayam yang terlalu tinggi memberikan pengaruh negatif diantaranya adalah meningkatkan kematian ayam broiler (Bergeron, Pouliot, \& Doyon, 2020).

Mortalitas dan bobot badan mingguan merupakan aspek yang harus diperhatikan dalam menentukan kepadatan ayam dalam kandang. Kepadatan yang tinggi dalam setiap meter persegi mengakibatkan ayam lebih mudah stres (Campoj, Gilm, \& Davila, 2005; Qaid, Albatshan, Shafey, Hussein, \& Abudabos 2016; Martindah \& Dhenastri 2020). Peningkatan kepadatan saat chick in biasanya diikuti dengan penurunan berat badan, konversi pakan, dan peningkatan mortalitas (Estevez, 2007; Onbașlla, Poyraz, Erdem, \& Őztűrk, 2008; Skomorucha Muchacka, Sosnowka-Czajka, \& Herbut, 2009). Penelitian terdahulu hanya membahas pengaruh satu faktor terhadap mortalitas dan bobot badan ayam, maka dari itu tujuan dari penelitian ini adalah untuk mengetahui pengaruh tingkat kepadatan dan strain ayam broiler serta interaksi keduanya, sebagai wujud interaksi antara genetik dan lingkungan terhadap mortalitas dan bobot badan.

\section{METODE PENELITIAN}

\section{Koleksi Data}

Catatan pemeliharaan ayam broiler diperoleh dari 60 kandang closed house dari 43 farm di Provinsi Jawa Tengah dengan rincian strain: $C o b b=27$ kandang, CP $707=13$ kandang, dan Loghman $=20$ kandang. Total populasi broiler selama periode koleksi data adalah 1.001 .988 ekor strain Cobb, 758.803 ekor strain CP 707, 839.888 strain Loghman. Kepadatan kandang dikelompokan menjadi tiga kategori; kandang dengan kepadatan $\leq 10$ ekor $/ \mathrm{m}^{2}$ (7 kandang), kandang dengan kepadatan $>10$ sampai $<15$ ekor $/ \mathrm{m}^{2}$ (27 kandang), dan kandang dengan kepadatan $\geq 15$ ekor $/ \mathrm{m}^{2}$ (26 kandang). Parameter yang diamati yaitu: mortalitas dan bobot badan. M1, M2, M3, M4, dan M5 berurutan untuk mortalitas minggu pertama sampai minggu kelima dan BB1, BB2, BB3, BB4, dan BB5 berurutan untuk bobot badan minggu pertama sampai minggu kelima.

Persen mortalitas dihitung dengan membagi jumlah ayam mati dengan jumlah ayam sejak awal pemeliharaan kemudian dikalikan dengan 100 persen (Zulfan \& Zulfikar, 2020). Bobot badan mingguan di timbang dari 40 ekor sampel dari setiap kandang. Mortalitas dan bobot badan ayam broiler dari tiga strain dan tingkat kepadatan kandang yang berbeda disajikan masing-masing pada Tabel 1 dan Tabel 2 .

\section{Analisis Statistik}

Analisis data mengunakan dua faktor (strain dan kepadatan) sebagai fixed effects dan farm sebagai random effect dengan mixed procedure pada Statistical Analysis System (SAS) University Edition V.6p.2. software (SAS, 2011). Model statistik yang digunakan sebagai berikut:

$$
y_{-} i j k=S_{-} i+D_{-} j+S_{-} i x D_{-} j+f_{-} k+e_{-} i j k
$$

dimana: yijk adalah mortalitas atau bobot badan mingguan Si fixed effects dari strain ke-i, Dj fixed effects dari kepadatan ke-j, Si x Dj fixed effects interaksi antara strain ke-i dan kepadatan ke-j, $f_{-} k$ random effect dari farm ke-k serta eij adalah random error dari yijk.

\section{HASIL DAN PEMBAHASAN}

Berdasarkan hasil analisis, strain tidak berpengaruh nyata $(\mathrm{P}>0,05)$ terhadap $\mathrm{M} 1$, M2, M3, M4 dan M5 (Tabel 3). Hal tersebut menunjukkan bahwa berbagai strain ayam broiler yaitu Cobb, CP707, dan Lohmann tidak memiliki efek signifikan terhadap mortalitas. Menurut (Torrey et al., 2021) berbagai strain ayam broiler tidak menunjukkan perbedaan mortalitas ayam broiler yang dipelihara dalam 
Tabel 1. Deskripsi statistik dari mortalitas ayam broiler dari strain dan tingkat kepadatan yang berbeda.

\begin{tabular}{|c|c|c|c|c|c|c|c|}
\hline \multirow{2}{*}{ Faktor } & \multirow{2}{*}{ Jumlah Farm } & \multirow{2}{*}{$\begin{array}{l}\text { Rata-rata } \\
\text { Populasi }\end{array}$} & \multicolumn{5}{|c|}{ Rata-rata $\pm \mathrm{SE}^{*}$} \\
\hline & & & M1(\%) & M2(\%) & M3(\%) & M4(\%) & M5(\%) \\
\hline \multicolumn{8}{|l|}{ Strain } \\
\hline$C o b b$ & 27 & 15.341 & $0,73 \pm 0,09$ & $0,65 \pm 0,05$ & $0,67 \pm 0,06$ & $0,81 \pm 0,17$ & $0,54 \pm 0,08$ \\
\hline CP707 & 13 & 12.237 & $0,84 \pm 0,22$ & $0,69 \pm 0,21$ & $0,66 \pm 0,14$ & $0,67 \pm 0,18$ & $0,55 \pm 0,12$ \\
\hline Loghman & 20 & 19.212 & $0,9 \pm, 20$ & $0,57 \pm 0,06$ & $0,97 \pm 0,26$ & $1,01 \pm 0,19$ & $0,66 \pm 0,15$ \\
\hline \multicolumn{8}{|c|}{ Kepadatan (ekor/m) } \\
\hline$\leq 10$ & 7 & 13.607 & $0,84 \pm 0,24$ & $0,63 \pm 0,12$ & $0,81 \pm 0,22$ & $1,34 \pm 0,54$ & $0,74 \pm 0,24$ \\
\hline$>10$ dan $<15$ & 27 & 13.266 & $0,94 \pm 0,16$ & $0,72 \pm 0,10$ & $0,71 \pm 0,11$ & $0,63 \pm 0,11$ & $0,46 \pm 0,07$ \\
\hline$\geq 15$ & 26 & 19.752 & $0,73 \pm 0,10$ & $0,54 \pm 0,04$ & $0,82 \pm 0,18$ & $0,94 \pm 0,15$ & $0,66 \pm 0,11$ \\
\hline
\end{tabular}

*SE=standar error

Tabel 2. Deskripsi statistik dari bobot badan ayam broiler dari strain dan tingkat kepadatan yang berbeda

\begin{tabular}{|c|c|c|c|c|c|c|c|}
\hline \multirow{2}{*}{ Faktor } & \multirow{2}{*}{ Jumlah Farm } & \multirow{2}{*}{$\begin{array}{l}\text { Rata-rata } \\
\text { populasi }\end{array}$} & \multicolumn{5}{|c|}{ Rata-rata $\pm \mathrm{SE}^{*}$} \\
\hline & & & BB1(kg) & BB2(kg) & BB3(kg) & BB4(kg) & BB5(kg) \\
\hline \multicolumn{8}{|l|}{ Strain } \\
\hline Cobb & 27 & 15.341 & $0,17 \pm 0,01$ & $0,43 \pm 0,02$ & $0,87 \pm 0,03$ & $1,46 \pm 0,05$ & $2,04 \pm 0,06$ \\
\hline CP707 & 13 & 12.237 & $0,16 \pm 0,01$ & $0,42 \pm 0,03$ & $0,91 \pm 0,02$ & $1,45 \pm 0,05$ & $2,16 \pm 0,04$ \\
\hline Loghman & 20 & 19.212 & $0,17 \pm 0,01$ & $0,46 \pm 0,01$ & $0,88 \pm 0,02$ & $1,43 \pm 0,03$ & $1,98 \pm 0,15$ \\
\hline \multicolumn{8}{|c|}{ Kepadatan (ekor/m) } \\
\hline$\leq 10$ & 7 & 13.607 & $0,18 \pm 0,01$ & $0,48 \pm 0,02$ & $0,93 \pm 0,03$ & $1,49 \pm 0,05$ & $2,12 \pm 0,08$ \\
\hline$>10$ dan $<15$ & 27 & 13.266 & $0,17 \pm 0,01$ & $0,43 \pm 0,02$ & $0,87 \pm 0,02$ & $1,46 \pm 0,04$ & $2,07 \pm 0,04$ \\
\hline$\geq 15$ & 26 & 19.752 & $0,17 \pm 0,01$ & $0,43 \pm 0,02$ & $0,88 \pm 0,03$ & $1,43 \pm 0,04$ & $2,03 \pm 0,13$ \\
\hline
\end{tabular}

*SE=standar error

kandang sistem closed house.

Tingkat kepadatan dari ayam broiler berpengaruh $(\mathrm{P}<0,01)$ terhadap $\mathrm{M} 1$, tetapi tidak perpengaruh terhadap M2, M3, M4 dan M5. Pengaruh kepadatan pada M1 berkaitan erat dengan adaptasi ayam terhadap kondisi kandang pada satu minggu setelah chick in. Gholami, Chamani, Seidavi, Sadeghi, \& Aminafschar (2020) melaporkan bahwa pemeliharaan ayam broiler di kandang closed house optimal pada kepadatan 17 ekor $/ \mathrm{m}^{2}$ sehingga angka mortalitas dapat ditekan. Jika tingkat kepadatan ayam broiler tersebut ditingkatkan hingga 20 ekor $/ \mathrm{m}^{2}$ maka diikuti juga meningkatnya angka mortalitas. Hasil pada M2 sampai M5 sesuai dengan penelitian Linhoss, Purswell, Magee, \& Chesser (2021) dan Türkyilmaz (2008) yang menjelaskan tingkat kepadatan tidak berpengaruh nyata terhadap mortalitas pada ayam pedaging.

Berdasarkan hasil penelitian strain dan tingkat kepadatan memberikan interaksi terhadap M1 $\quad(\mathrm{P}<0,01)$ dan $\mathrm{M} 4 \quad(\mathrm{P}<0,05)$.
Hal ini menunjukkan bahwa masing-masing strain mempunyai kemampuan yang berbeda dalam beradaptasi pada tingkat kepadatan kandang pada minggu pertama. Pada minggu ke-2 dan ke-3 tiga strain tidak menunjukkan perbedaan angka mortalitas pada semua tingkat kepadatan. Pada minggu ke-4, terdapat interaksi antara strain dan kepadatan dikarenakan pada minggu ini kepadatan dalam kandang mencapai puncaknya. Hasil penelitian ini sama dengan hasil riset yang dilakukan oleh Popoola, Bolarinwa, Ojetola, Oladiti, \& Kolawole (2017) yang melaporkan adanya pengaruh signifikan akibat interaksi antara kedua faktor terhadap performa ayam broiler. Rata-rata kepadatan kandang pada minggu ke-4 apabila di konversi kedalam $\mathrm{kg} / \mathrm{m}^{2}$ sebagai berikut: $\leq 14,9,15-22$ dan $\geq 15$. Setiap strain memiliki kemampuan yang berbeda pada masing-masing tingkat kepadatan tersebut. Pada minggu ke-5 biasanya mulai dilakukan seleksi ayam untuk dipanen (Ratnasari, Sarengat, \& Setiadi, 2015; Mariyam, 
Tabel 3. Analysis of varian untuk mortalitas minggu pertama sampai minggu kelima.

\begin{tabular}{|c|c|c|c|c|c|c|c|c|c|c|c|}
\hline \multirow{2}{*}{ Faktor } & \multirow{2}{*}{$\mathrm{db}^{*}$} & \multicolumn{2}{|c|}{ M 1} & \multicolumn{2}{|c|}{ M 2} & \multicolumn{2}{|c|}{ M 3} & \multicolumn{2}{|c|}{ M 4} & \multicolumn{2}{|c|}{ M 5} \\
\hline & & Nilai F & $\operatorname{Pr}>\mathrm{F}$ & Nilai F & $\operatorname{Pr}>\mathrm{F}$ & Nilai F & $\operatorname{Pr}>\mathrm{F}$ & Nilai F & $\operatorname{Pr}>\mathrm{F}$ & Nilai F & $\operatorname{Pr}>\mathrm{F}$ \\
\hline Strain & 2 & 1,26 & 0,317 & 0,35 & 0,709 & 1,25 & 0,319 & 1,97 & 0,179 & 0,27 & 0,764 \\
\hline Kepadatan & 2 & 16,02 & 0,003 & 3,51 & 0,061 & 0,03 & 0,975 & 1,45 & 0,269 & 0,57 & 0,581 \\
\hline Strain*kepadatan & 4 & 5,58 & 0,007 & 1,55 & 0,246 & 0,37 & 0,823 & 3,88 & 0,027 & 0,73 & 0,586 \\
\hline
\end{tabular}

$* \mathrm{db}=$ derajat bebas

Tabel 4. Analysis of varian untuk bobot badan minggu pertama sampai minggu kelima.

\begin{tabular}{|c|c|c|c|c|c|c|c|c|c|c|c|}
\hline \multirow{2}{*}{ Faktor } & \multirow{2}{*}{$\mathrm{db}^{*}$} & \multicolumn{2}{|c|}{ BB1 } & \multicolumn{2}{|c|}{ BB2 } & \multicolumn{2}{|c|}{ BB3 } & \multicolumn{2}{|c|}{ BB4 } & \multicolumn{2}{|c|}{ BB5 } \\
\hline & & Nilai F & $\operatorname{Pr}>F$ & Nilai F & $\operatorname{Pr}>\mathrm{F}$ & Nilai F & $\operatorname{Pr}>F$ & Nilai F & $\operatorname{Pr}>\mathrm{F}$ & Nilai F & $\operatorname{Pr}>F$ \\
\hline Strain & 2 & 0,03 & 0,969 & 0,01 & 0,997 & 0,10 & 0,905 & 0,25 & 0,786 & 0,20 & 0,821 \\
\hline kepadatan & 2 & 0,90 & 0,431 & 2,50 & 0,121 & 1,22 & 0,327 & 0,97 & 0,406 & 0,33 & 0,726 \\
\hline Strain*kepadatan & 4 & 0,40 & 0,806 & 2,31 & 0,113 & 1,28 & 0,329 & 1,72 & 0,205 & 0,60 & 0,668 \\
\hline
\end{tabular}

$* \mathrm{db}=$ derajat bebas

Tantalo, Riyanti, \& Septinova, 2020) sehingga kepadatan kandang akan berkurang dan berdampak pada angka mortalitas. Pada minggu ke-5 kepadatan menjadi tidak terukur karena waktu panen yang berbeda pada masing-masing farm, sehingga tidak terjadi interaksi antara strain dan kepadatan terhadap mortalitas.

Secara keseluruhan, angka mortalitas dalam penelitian ini dikatagorikan sangat rendah. Rendahnya angka mortalitas tersebut mengindikasikan pengelolaan budidaya ayam broiler tersebut sudah berjalan dengan baik dari segi manajemen kandang closed house, strain ayam yang bagus, ransum yang seimbang, vaksinasi ataupun obat-obatan sesuai dosis kebutuhan ayam broiler. Angka mortalitas yang baik yaitu jika angka mortalitas selama pemeliharaan di bawah $5 \%$ (Siaga, Baloyi, Rambau, \& Benyi, 2017; Martindah, \& Dhenastri 2020). Selain itu, angka mortalitas yang rendah menandakan kesejahteraan hewan terpenuhi.

Perbedaan strain dan kepadatan juga dapat dilihat dari indikator performa, salah satunya adalah bobot badan. Berdasarkan analisis statistik, strain tidak berpengaruh terhadap bobot badan baik BB1, BB2, BB3, BB4, dan BB5 (Tabel 4). Menurut Udeh, Isekwenu \& Ukughere (2011) perbedaan strain tidak menyebabkan perbedaan bobot badan yang signifikan, hal ini dikarenakan strain ayam broiler yang digunakan untuk komersil telah menggunakan strain yang mampu beradaptasi dengan lingkungan, sehingga produktivitasnya relatif sama jika mendapatkan pakan dan manajemen yang sama. Sesuai dengan pendapat Dwitama, Sundari, \& Suwarta (2021) bahwa strain ayam broiler tidak berpengaruh nyata terhadap peforma bobot badan ayam broiler.

Tingkat kepadatan ayam broiler tidak berpengaruh terhadap bobot badan ayam broiler baik BB1, BB2, BB3, BB4 maupun BB5. Mahfudz, Nurfaizin, Atmomarsono, \& Suthama (2015) melaporkan bahwa bobot badan ayam broiler minggu ke-4 dan ke-5 tidak dipengaruhi oleh tingkat kepadatan ayam broiler dalam kandang. Penelitian lain menyatakan bahwa performa ayam broiler akan mengalami perubahan jika kepadatan diatas 16 ekor $/ \mathrm{m}^{2}$ (Skrbic, Pavlovski, \& Lukic, 2009). Qaid, Albatshan, Shafey, Hussein, \& Abudabos (2016) melaporkan bahwa kepadatan berpengaruh terhadap performa broiler sampai umur dua minggu pada penelitian yang di desain dengan empat perlakuan kepadatan; 30, 60, 90, dan 120 ekor $/ \mathrm{m}^{2}$.

Tidak ada interaksi antara strain dan kepadatan kandang juga terhadap bobot badan mingguan pada ayam broiler. Hal ini menunjukkan bahwa ketiga strain mampu menunjukkan performa yang seimbang pada kepadatan kandang yang berbeda. Perusahaanperusahaan breeding farm Indonesia telah melakukan proses seleksi secara ketat. Seleksi dimulai dari telur sebelum ditetaskan sampai day old chicken (DOC) siap untuk diedarkan ke peternak. Ketiga strain ayam broiler dalam penelitian ini membuktikan sudah memiliki kemampuan adaptasi yang baik terhadap lingkungan terutama pada kandang closed 
house. Berdasarkan hasil penelitian (Weimer, Mauromoustakos, Karcher, \& Erasmus, 2020) bahwa strain ayam broiler yang dikembangkan merupakan hasil seleksi yang ketat dan diadaptasikan dengan kondisi lingkungan.

\section{KESIMPULAN}

Tiga strain ayam broiler yang dipelihara oleh peternak di Jawa Tengah mampu beradaptasi dengan baik pada berbagai tingkat kepadatan kandang. Interaksi antara genetik dan lingkungan terhadap mortalitas terjadi pada minggu pertama setelah chick in dan menjelang panen

\section{DAFTAR PUSTAKA}

Bell, D. D., \& Weaver, W. D. (2002). Book Review Commercial Chicken Meat and Egg Production 5th Edition. New York: Springer Science and Business Media.

Bergeron, S., Pouliot, E., \& Doyon, M. (2020). Commercial poultry production stocking density influence on bird health and performance indicators. Animals. 10, 1253. 1-8. doi:10.3390/ani10081253

Campoj, L., Gilm, G., \& Davila, S.G. (2005). Effect of intermingling chicks and bird density on fear and stress responses in chickens. Archiv fur Geflügelkunde, 69(5), 199-205.

Dwitama, D.V., Sundari, S., \& Suwarta, F. (2021). Kinerja produksi dua strain ayam broiler pada peternak mitra P.T. Cemerlang Unggas Lestari. Universitas Mercu Buana, Yogyakarta [Skripsi].

Estevez, I. (2007). Density allowances for broilers: where to set the limits?. Poultry Sceince, 86, 1265-1272. https://doi. org/10.1093/ps/86.6.1265

Gholami, M., Chamani, M., Seidavi, A., Sadeghi, A. A., \& Aminafschar, M. (2020). Effects of stocking density and environmental conditions on performance, immunity, carcase characteristics, blood constitutes, and economical parameters of cobb 500 strain broiler chickens. Italian Journal of Animal Science, 19(1), 524-535. https:// doi.org/10.1080/1828051X.2020.1757522

Hall, A.L. (2001). The effect of stocking density on the welfare and behaviour of broiler chickens reared commercially. Animal Welfare, 10,23-40.

Linhoss, J., Purswell, J., Magee, C., \& Chesser, D. (2021). Research Note: Effect of stocking density on crop fill progression in broilers grown to $14 \mathrm{~d}$. Poultry Science, 100(3),1-6. https://doi.org/10.1016/j.psj.2020.11.080

Mahfudz, L.D., Nurfaizin, Atmomarsono, U., \& Suthama, N. (2015). Interactive effect of cage density and dietary black cumin level on productive efficiency in broiler chickens. Journal of the Indonesian Tropical Animal Agriculture, 40(1). 37-44.

Mahmud, A. T. B. A., Afnan, R., Ekastuti, D. R., \& Arief, I. I. (2017). Profil darah, performans dan kualitas daging ayam persilangan kampung broiler pada kepadatan kandang berbeda. Jurnal Veteriner, 18(2), 247-256. https://doi.org/10.19087/ jveteriner.2017.18.2.247

Mariyam, S., Tantalo, S., Riyanti., R., \& Septinova, D. (2020). Pengaruh kepadatan kandang terhadapkonsumsi ransum, pertambahan berat tubuh dan konversi ransum broiler umur 14-28 hari di closed house. Jurnal Riset dan Inovasi Peternakan, 4(1):35-40. https://doi.org/10.23960/ jrip.2020.4.1.35-40

Martindah, E., \& Dhenastri, V.O. (2020). Tingkat mortalitas dan afkir ayam broiler di kandang terbuka dan tertutup (mortality rate and culling of broiler in the open and closed house). https://doi.org/10.14334/ Pros.Semnas.TPV-2020-p.692-702

Muwarni, R. (2010). Broiler Modern. Semarang: Widya Karya.

Onbaşılar, E.E.,Poyraz Ő.,Erdem E., \& Őztűrk H. (2008). Influence of lighting periods and stocking densities on performance, carcass characteristics and some stress parameters in broiler, Archiv fur Geflügelkunde, 72(5), 193-200.

Popoola, M. A., Bolarinwa, M. O., Ojetola, 0.0., Oladiti, O. C., \& Kolawole O. P. (2017). Evaluation of effects of a strain, stocking density and age on bilateral symmetry of broiler chickens. Slovak Journal of Animal Science. 50(2). 95-100

Qaid, M., Albatshan, H., Shafey, T., Hussein, E., \& Abudabos, A. M. (2016). Effect of stocking density on the performance and immunity of 1-to 14-d- old broiler chicks. Revista Brasileira de Ciencia Avicola, 18(4), 683-692. https://doi. org/10.1590/1806-9061-2016-0289

Ratnasari, R., Sarengat, W., \& Setiadi, A (2015). Analisis pendapatan peternak ayam broiler pada sistem kemitraan di kecamatan Gunung Pati Kota Semarang. Animal Agriculture Journal, 4(1): 47-53.

SAS. (2011). Sas/Stat 9.3. SAS Institute Inc., Cary, NC, 8640. Retrieved from http://scholar.google.com/ cholar?hl=en\&btnG=Search\&q=intitle:Sas / 
stat+9.3\#1

Siaga, R., Baloyi, J.J., Rambau, M.D., \& Benyi K. (2017). Effects of stocking density and genotype on the growth performance of male and female Broiler chickens. Asian Journal of Poultry Science, 11: 96-104.

Skomorucha, I., Muchacka, R., Sosnowka-Czajka, E. \& Herbut, E. (2009). Response of broiler chickens from three genetic groups to different stocking densities. Annals Animal Science, 9(2), 175-184. Retrieved from https://www.researchgate.net/ publication/285668020

Skrbic, Z., Pavlovski, Z., Lukic, M. (2009). Stocking density-factor of production performance, quality and broiler welfare. Biotechnology in Animal Husbandry 25 (5-6), 359-372.

Susanti, E. D., Dahlan, M., \& Wahyuning, D. (2016). Perbandingan produktivitas ayam broiler terhadap sistem kandang terbuka (open house) dan kandang tertutup (closed house) di UD Sumber Makmur Kecamatan Sumberrejo Kabupaten Bojonegoro. Jurnal Ternak, 7(1). https:// doi.org/10.30736/jy.v7i1.5

Torrey, S., Mohammadigheisar, M., Nascimento dos Santos, M., Rothschild, D., Dawson, L. C., Liu, Z., ... Widowski, T. M. (2021). In pursuit of a better broiler: growth, efficiency, and mortality of 16 strains of broiler chickens. Poultry Science, 100(3). https://doi.org/10.1016/j.psj.2020.12.052
Türkyilmaz, M.K. (2008). The effect of stocking density on stress reaction in broiler chickens during summer. Turkish Journal of Veterinary and Animal Sciences, 32(1),31-36.

Udeh, I., Isikwenu, J.0., \& Ukughere, G. (2011). Performance characteristics and prediction of bodyweightng linier body measurments in four strain of broiler chicken. International Journal of Animal and Veterynary Advances 3 (1), 44-46.

Weimer, S. L., Mauromoustakos, A., Karcher, D. M., \& Erasmus, M. A. (2020). Differences in performance, body conformation, and welfare of conventional and slowgrowing broiler chickens raised at 2 stocking densities. Poultry Science, 99(9), 4398-4407. https://doi.org/10.1016/j. psj.2020.06.009

Zulfan, \& Zulfikar. (2020). evaluasi performa dan income over feed \& chick cost (IOFCC) tiga strain ayam broiler yang beredar di Aceh. Jurnal Agripet, 20 (2), 136-142. https:// doi.org/10.17969/agripet.v20i2.15410 